\title{
A decade of ground support research at the WA School of Mines
}

\author{
E. Villaescusa Western Australian School of Mines, Curtin University/CRC Mining, Australia
}

A.G. Thompson Western Australian School of Mines, Curtin University/CRC Mining, Australia

J.R. Player Western Australian School of Mines, Curtin University/CRC Mining, Australia

\begin{abstract}
Mining in Western Australia during the next two decades or so will be approaching depths in which the induced stress regimes will approach the strength of the rock masses surrounding excavations. In such conditions, failure may occur violently due to the energy stored within the rock masses. Furthermore, in those highly stressed regions of a rock mass, sudden slip on major structures in the vicinity of the excavations are more likely to occur with an associated release of energy in the form of pressure and shear waves that excite the rock near the boundaries of excavations. In order to be prepared for such scenarios, and to ensure safe and economical excavations in the future, the Western Australian School of Mines (WASM) and a number of sponsoring companies have conceptualised and undertaken a number of research projects in ground support technology. The projects range from static and dynamic laboratory testing of support and reinforcement elements to in situ field testing and assessments of ground support corrosivity. The backgrounds for each of the stabilisation research projects at WASM have been summarised together with details of the methodology, current status, practical applications and future work.
\end{abstract}

\section{Introduction}

The purpose of ground support is to maintain excavations safe and open for their intended lifespan. The effectiveness of a support strategy is important for two main reasons; namely, safety for personnel and equipment and the most economical extraction of ore. The type of ground support needed in a particular location is dependent on several factors including the rock mass strength, the geometry of the excavation, the induced stresses, the blasting practices and the weathering processes. In most mining operations, the ground support design is based on previous experience and evolves over a number of years (Brown, 2004). In many instances, there may be nothing technically wrong with the designs and the performance can be assessed to be acceptable. However, rock mass conditions usually change with time (for example, stresses increase as the depth of mining increases and when the global extraction increases) and, accordingly, ground support performance may change and become unacceptable.

Over the last decade, the Western Australian School of Mines (WASM) has undertaken (in conjunction with a number of sponsoring companies) applied research to characterise rock masses and their responses to mining activities. To avoid uncontrolled rock mass failure, it is necessary to understand more fully the pre-existing rock mass conditions and stresses, optimise excavation design and extraction sequencing, and to install ground support that is resistant to both static and dynamic loadings. Some of the WASM ground support projects are described in the following sections.

\section{Static laboratory testing of rock reinforcement systems}

Laboratory testing provides a controlled environment where comparisons of capacity and load transfer for a given amount of deformation can be established. The tests can be specifically designed to determine the energy absorption of complete reinforcement systems. The example results presented herein relate to devices that were centralised and encapsulated with cement grout inside steel pipes $(45 \mathrm{~mm}$ internal diameter with $5 \mathrm{~mm}$ wall thickness). The pipes were split across their long axis to simulate a geological 
discontinuity at a distance of $1.0 \mathrm{~m}$ from the collar end (Figure 1). The cement grout was cured in excess of 28 days prior to testing, and the specimens were pulled until at least $100 \mathrm{~mm}$ of displacement occurred (Villaescusa et al., 1992). The loads and the displacement at the pipe split were monitored electronically throughout the tests and the data saved for processing.

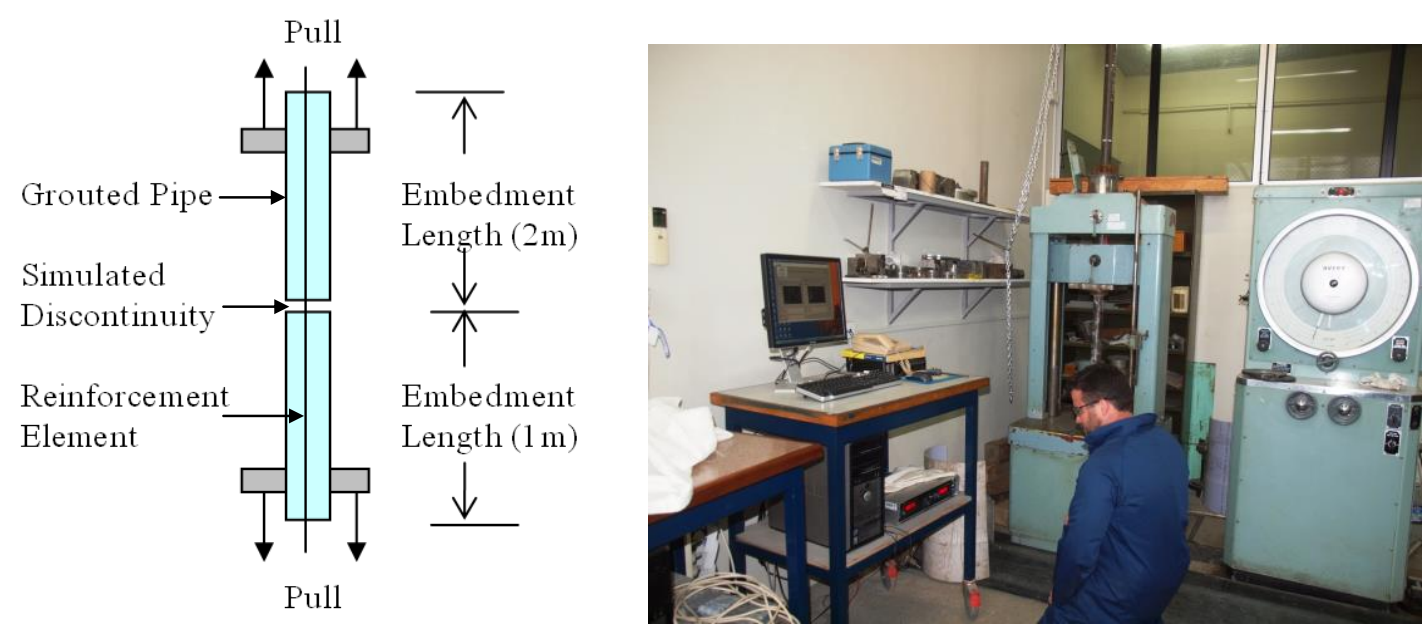

Figure 1 Schematic of split pipe geometry and actual static testing at WASM

Figure 2 shows details of a typical bolt spanning across a simulated discontinuity and plate/nut assemblies following static testing. Plate damage may range from little or no damage to catastrophic failure (inverted).

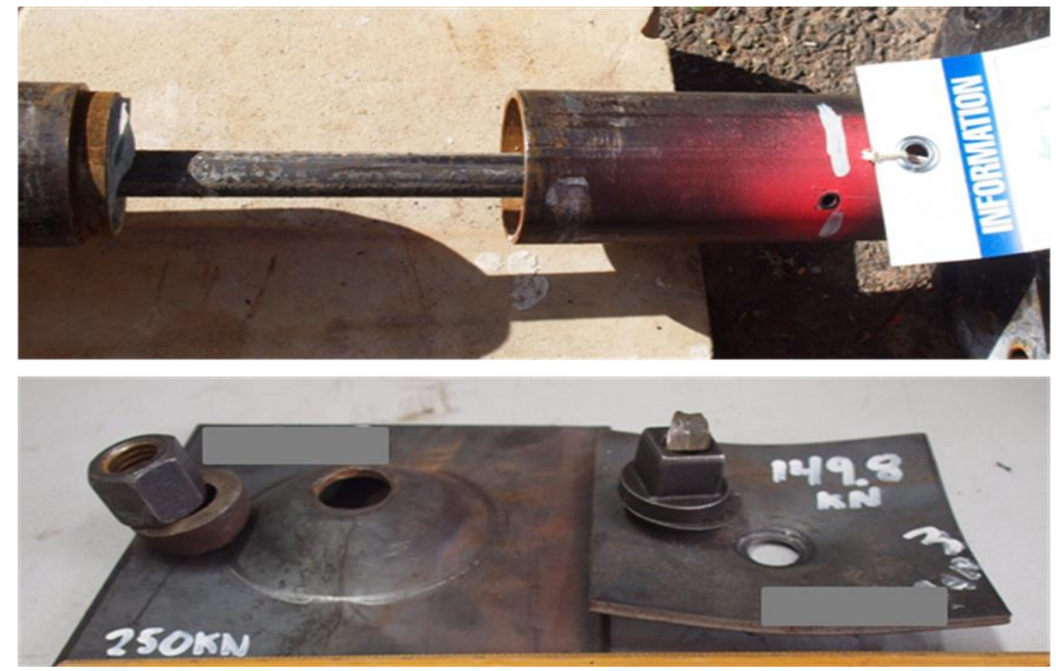

\section{Figure 2 Inspection of simulated discontinuity and plate/nut assemblies following static testing}

Figure 3 shows typical static testing results of double embedment testing carried out at WASM. The example results show that, for each reinforcement system, the results were very consistent with each other and in some cases, the plate inversion mechanism is clearly identifiable. The system performance for each commercial product can be compared based upon initial stiffness, peak and residual load (Thompson et al., 2012).

Following axial testing, the pipes can be slotted along their axes and separated to allow inspection of the load transfer mechanism for a particular reinforcement system. An example of the plowing mechanism of a Yield-Lok bolt can be seen in Figure 4. Thermal softening and flow of the polymer around the bolt 'upset' during dynamic loading have been reported by Wu and Oldsen (2010). The anchoring zone becomes critical to provide confinement to the bolt upset. Therefore, full encapsulation of the bolt is required and strongly recommended. This is contrary to the statement by $\mathrm{Wu}$ and Oldsen (2010) where they state that 'the 
performance of the Yield-Lok is basically independent of the type of grouting media, mixing status and drillhole diameter'.

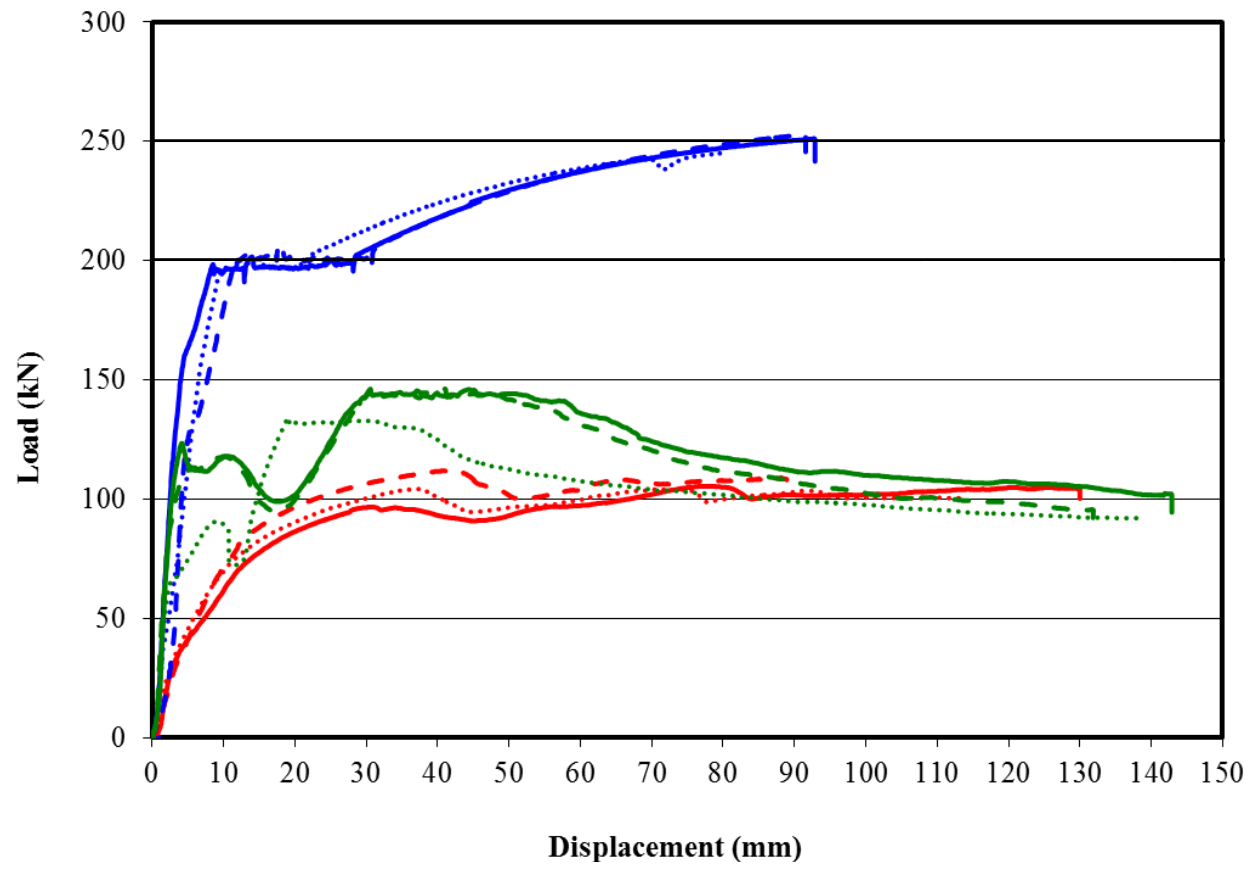

Figure 3 A comparison of typical load-displacement for three commercially available reinforcing systems

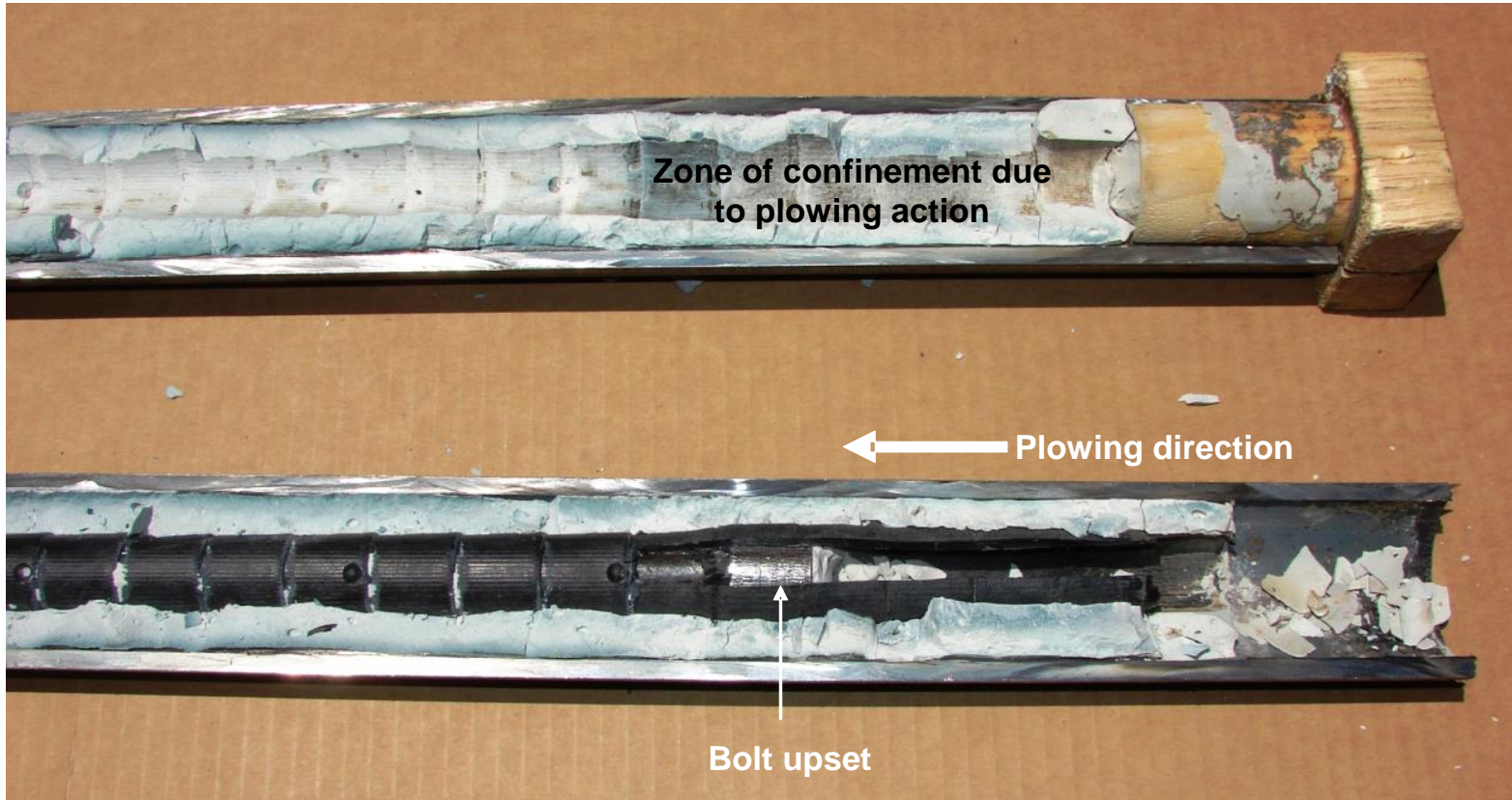

Figure 4 Longitudinal section view following static testing - Yield-Lok bolt

\section{Dynamic laboratory testing of rock reinforcement systems}

An understanding is also required of the dynamic energy absorption capabilities of individual reinforcement and support systems, as well as complete ground support schemes. This is particularly true when dynamic failures leading to rock mass ejection are being experienced. As a result, WASM secured industry and Western Australian government (MERIWA) sponsorship to develop a dynamic loading simulation facility using a new method of testing (Player et al., 2004; Thompson et al., 2004; Villaescusa et al., 2005; Player, 2012). To date the WASM Dynamic Test Facility (Figure 5) has the ability to test reinforcement and support 
systems. It is expected, that in the near future, complete ground support schemes will be tested dynamically as part of the current MERIWA Project M417.

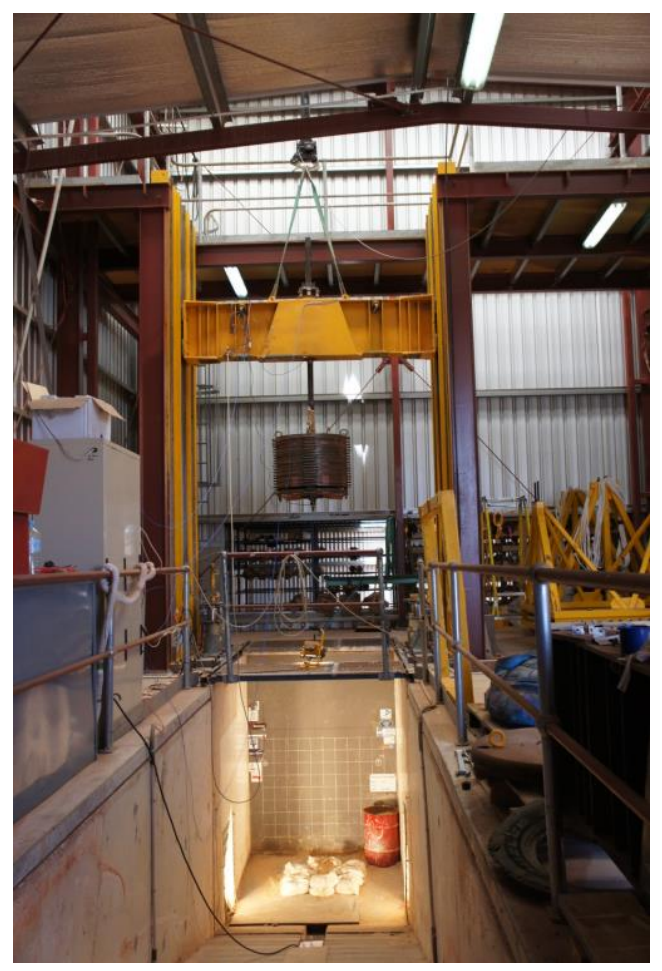

a)

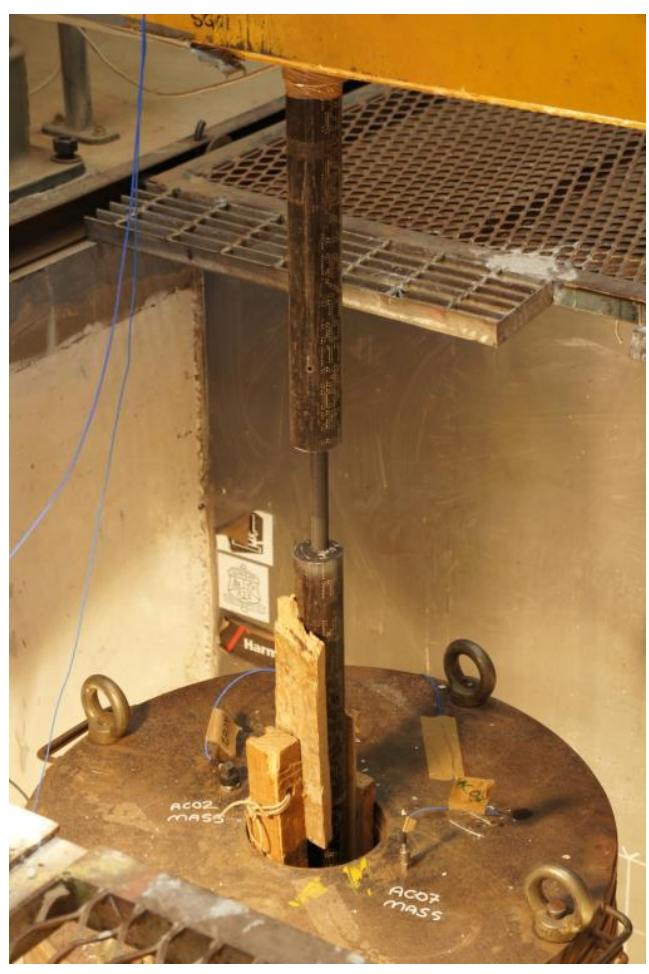

b)

Figure 5 a) General view of the WASM dynamic test facility; b) following a dynamic testing of a reinforcement system

Similarly to static testing, the WASM Dynamic Test Facility uses thick-walled steel pipes to simulate the rock mass, the borehole and a reinforcement system using the load transfer concept (Windsor and Thompson, 1993) by having (Figure 6):

- An anchor zone consisting of the beam and the upper pipe.

- A collar zone consisting of the loading mass and the lower pipe.

- An element which spans between the anchor and collar zones. 

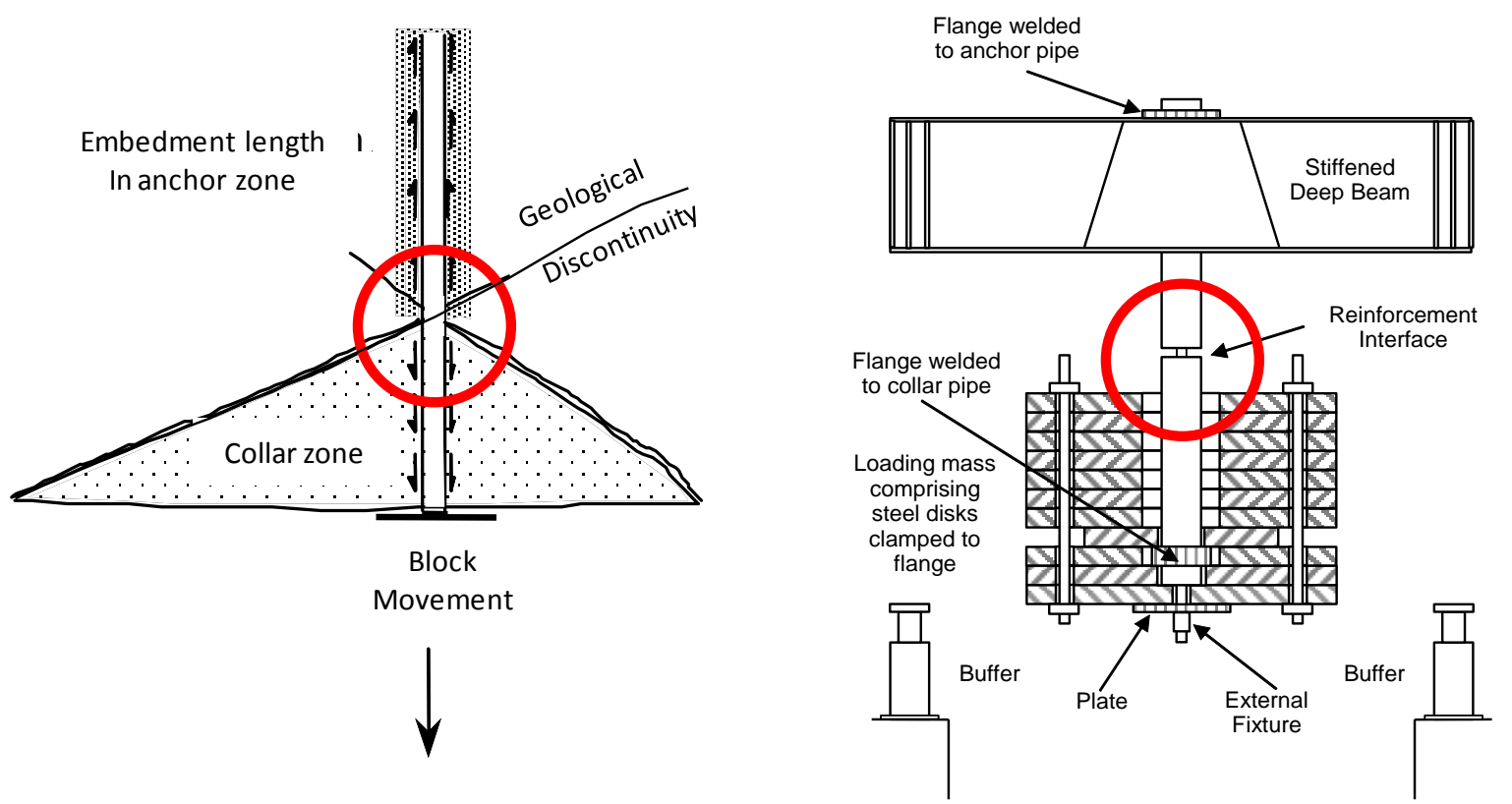

Figure 6 Reinforcement simulation under laboratory conditions

A typical test involves raising the beam with the reinforcement system to be tested to heights of up to $5 \mathrm{~m}$. A loading mass of approximately $2,000 \mathrm{~kg}$ is attached to the lower end of the specimen. The complete assembly is then dropped. In tests to date, the impact surfaces are buffers similar to those used to absorb collisions between train locomotives and carriages (Player, 2012). Figure 7 show the sequence of steps in the test of a reinforcement system. After impact, the beam and upper pipe are retarded by the buffers. At the same time, the element attempts to slow the loading mass. The ability of the reinforcement system as a whole to successfully retard the loading mass depends on its response characteristics. The response characteristics are typically how much it deforms when subject to load, as well as both the force and displacement capacities. With these measured characteristics, it is possible to calculate the energy absorption (Thompson et al., 2004); this is the criterion by which different reinforcement systems may be compared (Thompson et al., 2012).

The establishment of the WASM Dynamic Test Facility required the integration of a new test method with several different modes of measurement. Measurements are made using electrical resistance strain gauges and load cells, ultrasonic and potentiometric displacement sensors and accelerometers. In addition, all tests are monitored visually using a high speed digital video camera. All these instruments are monitored and synchronised using a high speed data acquisition and recording system. Finally, computer software was developed to view and analyse efficiently the large quantity of data collected during each test. Figure 8 shows a catastrophic failure of a commercially available reinforcement system that occurred during dynamic loading with approximately 2 tonnes @ $6 \mathrm{~m} / \mathrm{s}$ resulting in an ejection velocity of $5 \mathrm{~m} / \mathrm{s}$. 


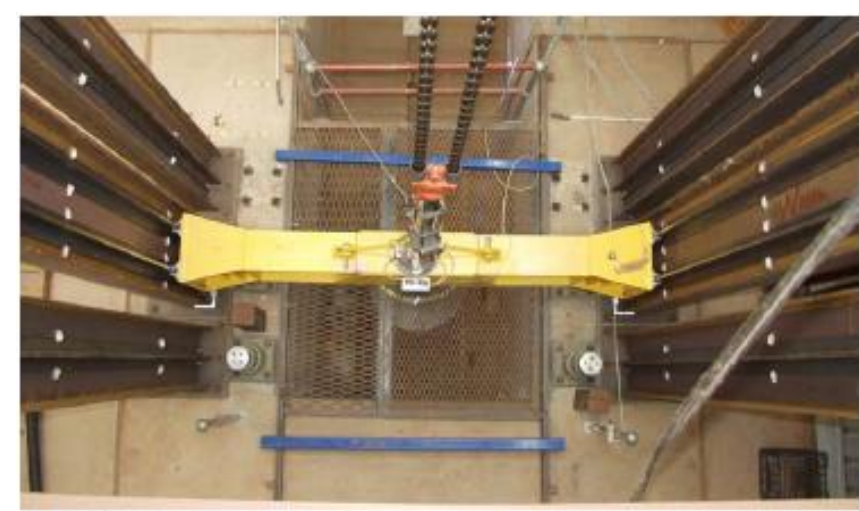

Beam resting on

the buffers at the

start of a test

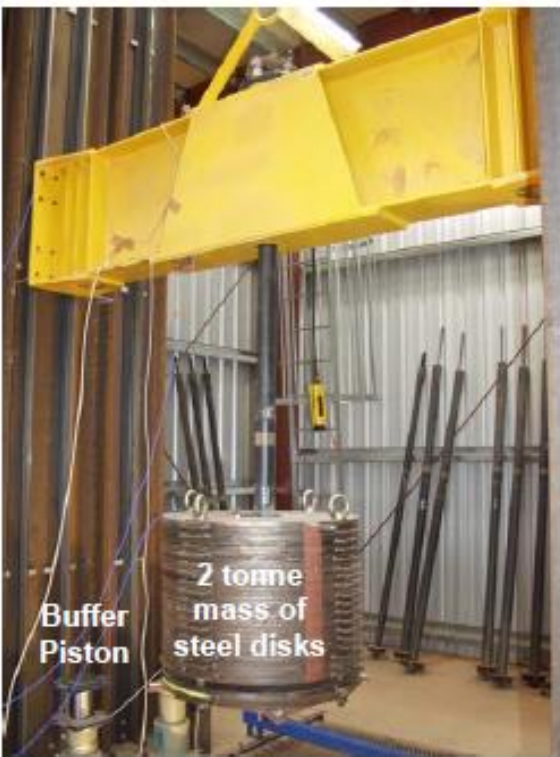

Beam raised to a height of about $2 \mathrm{~m}$

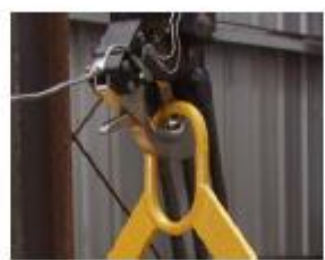

Drop initiated by electronic

release

mechanism

Figure 7 Sequence of steps during dynamic testing of rock reinforcement at WASM

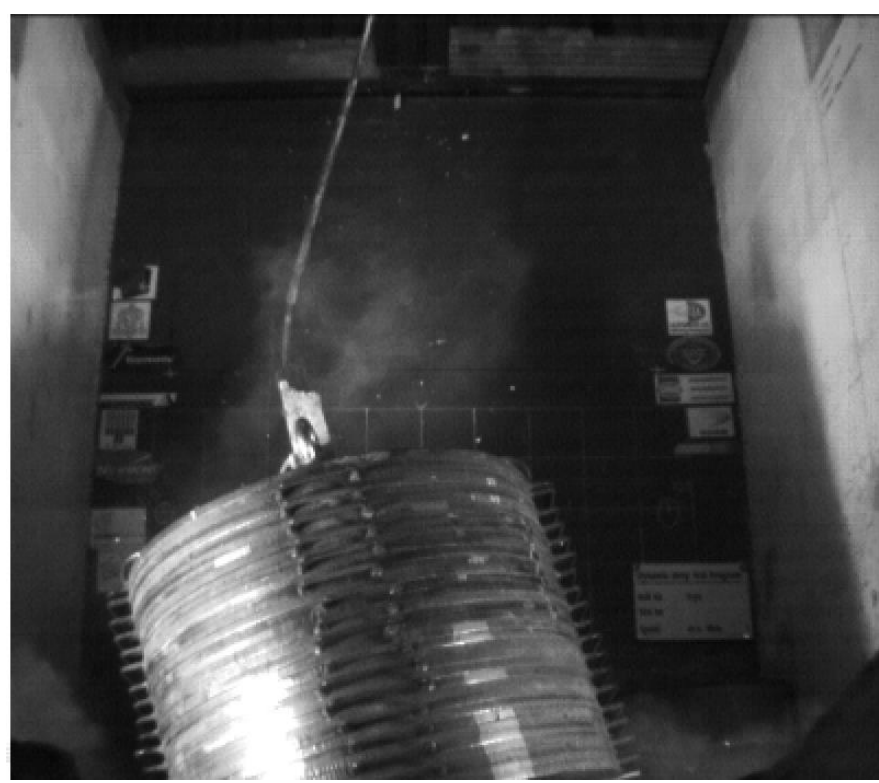

Figure 8 Catastrophic failure of a reinforcement system 


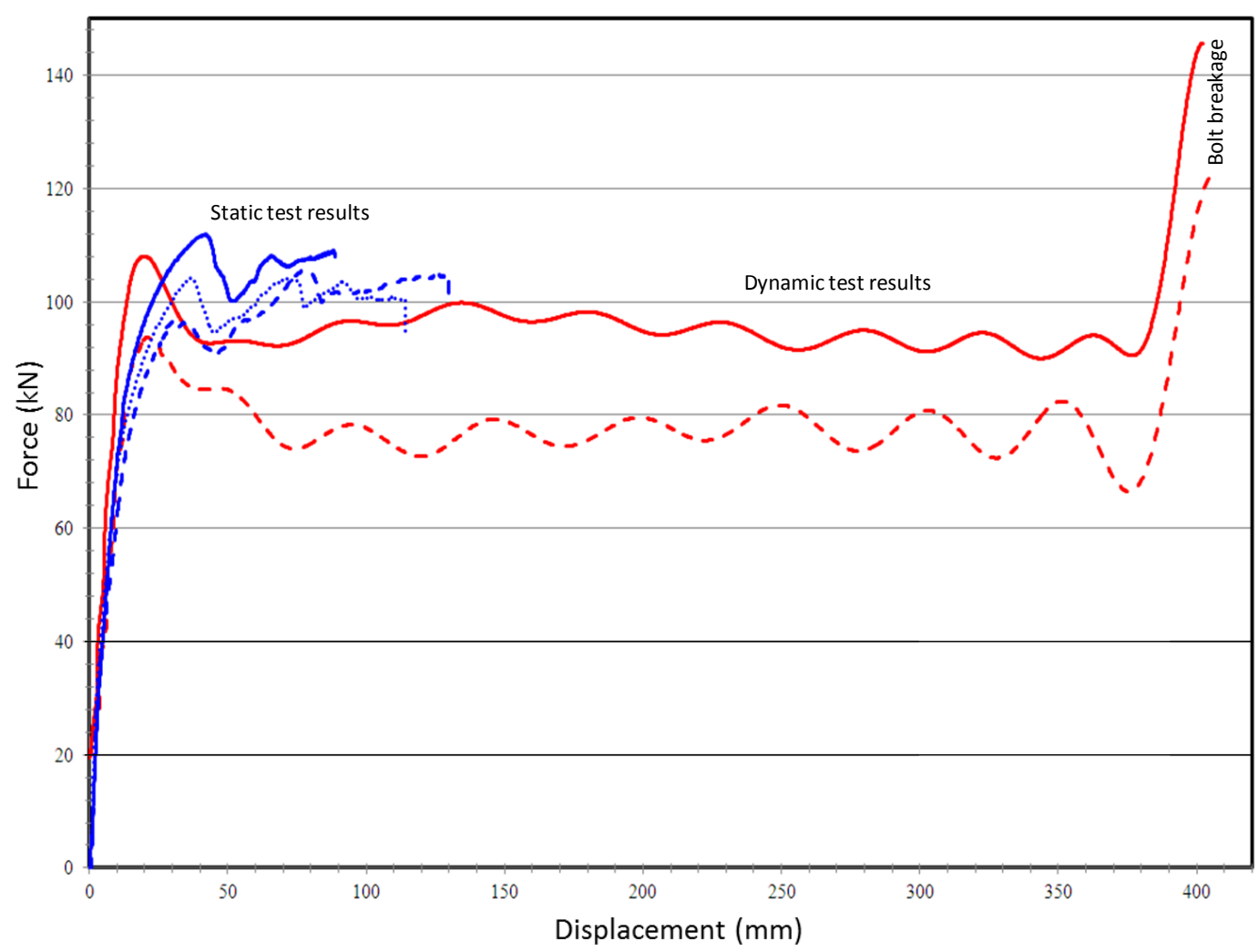

Figure 9 An example of the comparison of static versus dynamic behaviour

Research to date has been focused on developing performance criteria for comparison of a number of commercially available reinforcement systems. Comparisons based solely on energy absorbed are not sufficient, and the analysis must include for example dynamic force-displacement responses as well as practical considerations for total displacement allowed before rock mass unraveling occurs. Displacement is particularly important. For example, although a reinforcement system may have large displacement capacities (and hence high energy absorption due to the change in potential energy of the mass following impact), it may cause the rock mass to disintegrate to the point where the support system may not be able to hold the broken rock. Figure 10 shows a summary of WASM results for elements other than friction rock stabilisers (Player, 2012). 


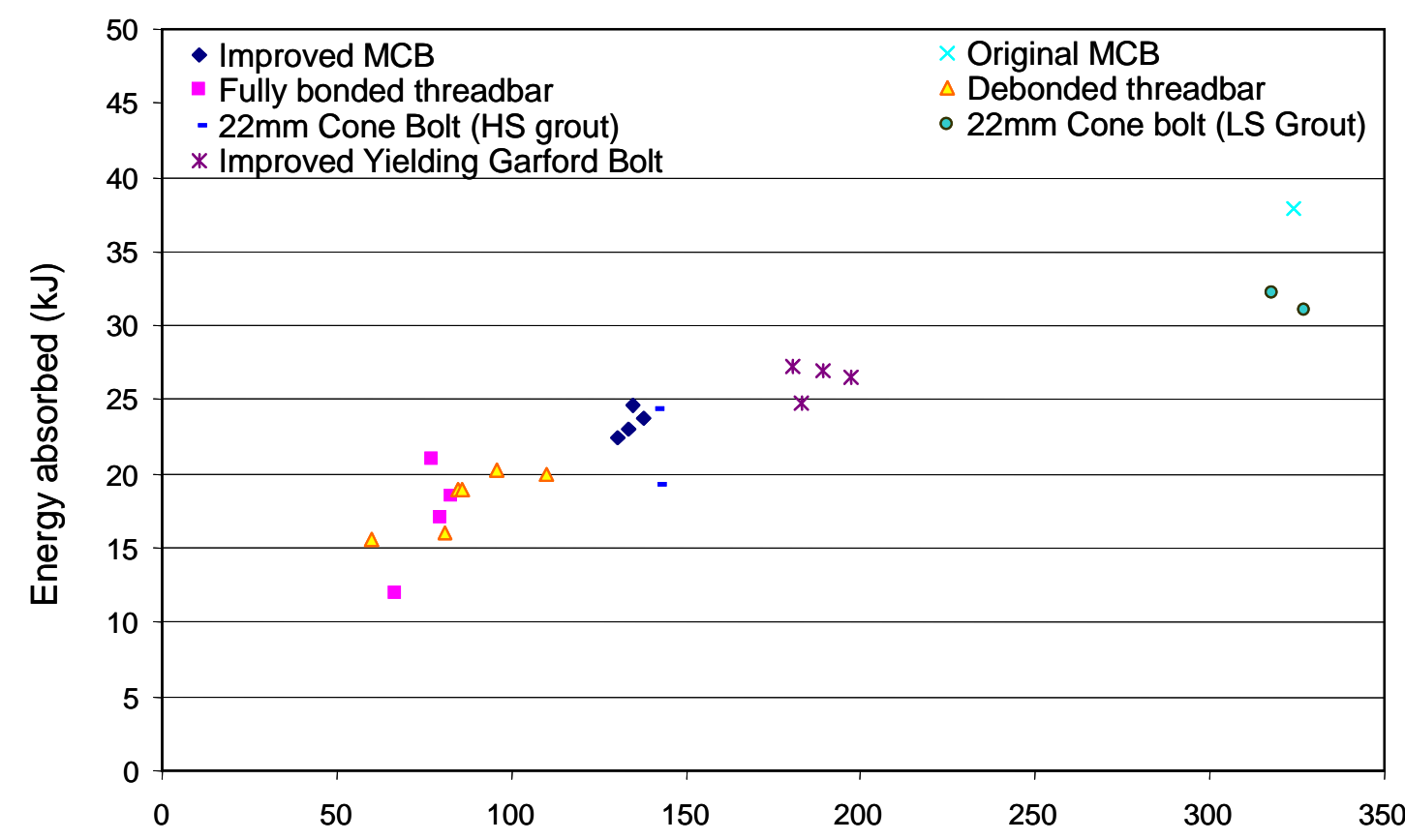

Separation at the simulated discontinuity $(\mathrm{mm})$

\section{Figure 10 Energy absorbed compared with deformation for a number or reinforcement systems (Player, 2012)}

\section{Cable bolt corrosion}

Corrosion is one of the major factors determining which steel based reinforcement and surface types can be used as permanent ground support. Corrosion reduces the capacity and life expectancy of ground support creating a number of safety concerns and operational difficulties in underground mining (Villaescusa et al., 2008). Furthermore, corrosion has been found to be partly responsible for $29 \%$ of all rockbolt failures and $25 \%$ of all cable bolt failures during rock falls within the Australian mining industry (Potvin et al., 2001).

\subsection{Corrosivity of cable bolt strands}

Cement grouted cable bolts have a high load transfer capacity and resistance to corrosion damage. This resistance is provided by the protective alkaline environment of the cement grout and the physical barrier it provides from the surrounding environment. However, experience has shown that corrosion begins once the cement grout barrier is removed. This occurs after cracking of the grout column due to ground movement, blast damage, or in sections where the element is exposed due to inadequate encapsulation during installation.

In an effort to better understand the response of cement grout encapsulated strands to corrosion attack following cracking of the grout column and infiltration of groundwater, laboratory experiments including data collection at eight Australian Mines have been reported by Hassell et al. (2004) and Hassell (2008). The research concluded that at least a $2 \mathrm{~mm}$ crack width is needed before significant corrosion occurs. Variables such as $\mathrm{pH}$, temperature, total dissolved solids (TDS), dissolved oxygen, flow rate and time were analysed. A very good direct linear relationship was found between the measured corrosion rates and dissolved oxygen (Figure 11). Dissolved oxygen content was found to be directly related to the temperature and salinity of the water. Thus with one parameter, three controlling variables can be taken into account (Hassell, 2008). The good correlation between corrosion rate and TDS is partly due to the temperatures being similar and having a comparable effect on the corrosion rate. 


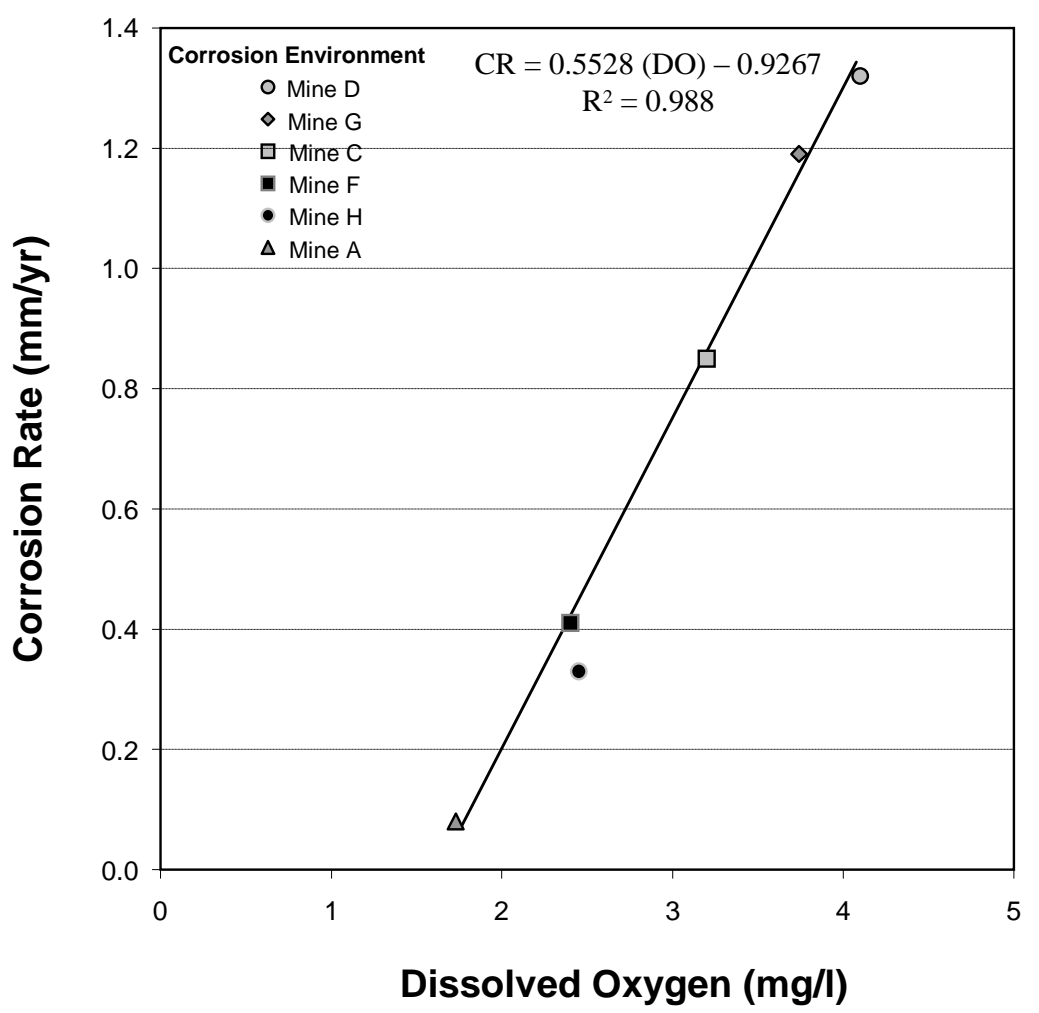

\section{Figure 11 Dissolved oxygen versus corrosion rates for a number of Australian mines (Hassell, 2008)}

In general, a reduction in the rate of corrosion over time was observed. This is due to the corrosion products partly inhibiting further corrosion. This rate becomes constant after a certain period of time, depending on the environmental conditions.

The rate of groundwater flow increases the corrosion rate by two processes. Firstly, increases in the flow rate simultaneously increase the rate at which dissolved oxygen is brought into contact with the steel surface to provide more available oxygen for the electrochemical process. Secondly, higher flow rates also increase the level of physical erosion of the corrosion products and reduce the thickness of the partially protective cover.

Table 1 shows the corrosivity classification proposed by Hassell (2008) for groundwater-affected, hard rock conditions found in Australian underground mines. The classification considers two factors in determining the corrosivity, the groundwater; dissolved oxygen content as measured in situ from a dissolved oxygen probe and the groundwater flow conditions as illustrated in Figure 12. Uniform corrosion rates for HA300 grade steel can then be estimated for different environments.

The classification provides a range of possible corrosion rates for a specific dissolved oxygen content and groundwater flow. As the groundwater condition is obtained from qualitative observation rather than quantitative assessment, this variation in values is necessary. Projections of the corrosion rates for measurements of dissolved oxygen less than $1.5 \mathrm{mg} / \mathrm{l}$ and greater than $4.5 \mathrm{mg} / \mathrm{l}$ is uncertain due to insufficient data. The given corrosion rates are for uniform corrosion only. However, it is appropriate to assume that pitting corrosion will increase with higher rates of uniform corrosion. The classification does not take into account the rock mass quality. It is assumed that if the classification is to be applicable, the reinforcement will intersect water bearing discontinuities. In addition, the rock mass damage from stress redistribution is expected to increase the permeability within the zones where reinforcement is utilised.

Approximate minimum and maximum service lives have been estimated from measurements made in corrosion chamber experiments (Hassell, 2008). The service life is estimated from the material loss required to cause failure of the strand loaded to $175 \mathrm{kN}$ or approximately 17.5 tonnes, a $30 \%$ decrease in the original 
capacity of $250 \mathrm{kN}$. Groundwater is assumed to be present and it is assumed that either cracking of the grout column has occurred or grout encapsulation is poor. Comparing the measured service lives with the corresponding corrosion rates of the simulated environment calculated using the corrosivity classification, estimates can be made to the expected minimum and maximum service lives $(<17.5 \mathrm{kN})$ of $15.2 \mathrm{~mm}$ diameter black strand over a range of corrosion rates as shown in Figure 13.

It is estimated, that even in the most corrosive conditions observed in underground mines, cable strand will last at least one year once cracks along the element axis have formed. This figure is much higher than the expected life of uncoated barrel and wedge anchors, found to be approximately seven months in similar corrosive conditions (Hassell et al., 2006).

Table 1 Maximum corrosion rates for HA300 steel in groundwater affected Australian hard rock mining environments (Hassell, 2008)

\begin{tabular}{|c|c|c|c|c|}
\hline \multicolumn{5}{|c|}{ Strong flow - Large continuous water flow from a large fault or many fractures } \\
\hline Dissolved oxygen (mg/l) & $1-2$ & $2-3$ & $3-4$ & $4-5$ \\
\hline Corrosion rate (mm/yr) & $<0.12$ & $0.12-0.36$ & $0.36-0.58$ & $0.58-0.8$ \\
\hline \multicolumn{5}{|c|}{ Flowing - Water flows from fractures } \\
\hline Dissolved oxygen (mg/l) & $1-2$ & $2-3$ & $3-4$ & $4-5$ \\
\hline Corrosion rate (mm/yr) & $<0.09$ & $0.090-0.225$ & $0.225-0.365$ & $0.365-0.50$ \\
\hline \multicolumn{5}{|c|}{ Dripping - Numerous drips and trickling of water from fractures } \\
\hline Dissolved oxygen (mg/l) & $1-2$ & $2-3$ & $3-4$ & $4-5$ \\
\hline Dissolved oxygen (mg/l) & $<0.06$ & $0.060-0.105$ & $0.105-0.160$ & $0.16-0.20$ \\
\hline \multicolumn{5}{|c|}{ Wet - Rock mass discoloured. Dripping from fractures moderately common } \\
\hline Dissolved oxygen (mg/l) & $1-2$ & $2-3$ & $3-4$ & $4-5$ \\
\hline Corrosion rate (mm/yr) & $<0.04$ & $0.040-0.075$ & $0.075-0.100$ & $0.10-0.12$ \\
\hline \multicolumn{5}{|c|}{ Damp - Rock mass is discoloured from dry rock mass. Very minor drips } \\
\hline Dissolved oxygen (mg/l) & $1-2$ & $2-3$ & $3-4$ & $4-5$ \\
\hline Corrosion rate (mm/yr) & $<0.02$ & $0.020-0.030$ & $0.030-0.040$ & $0.04-0.05$ \\
\hline
\end{tabular}




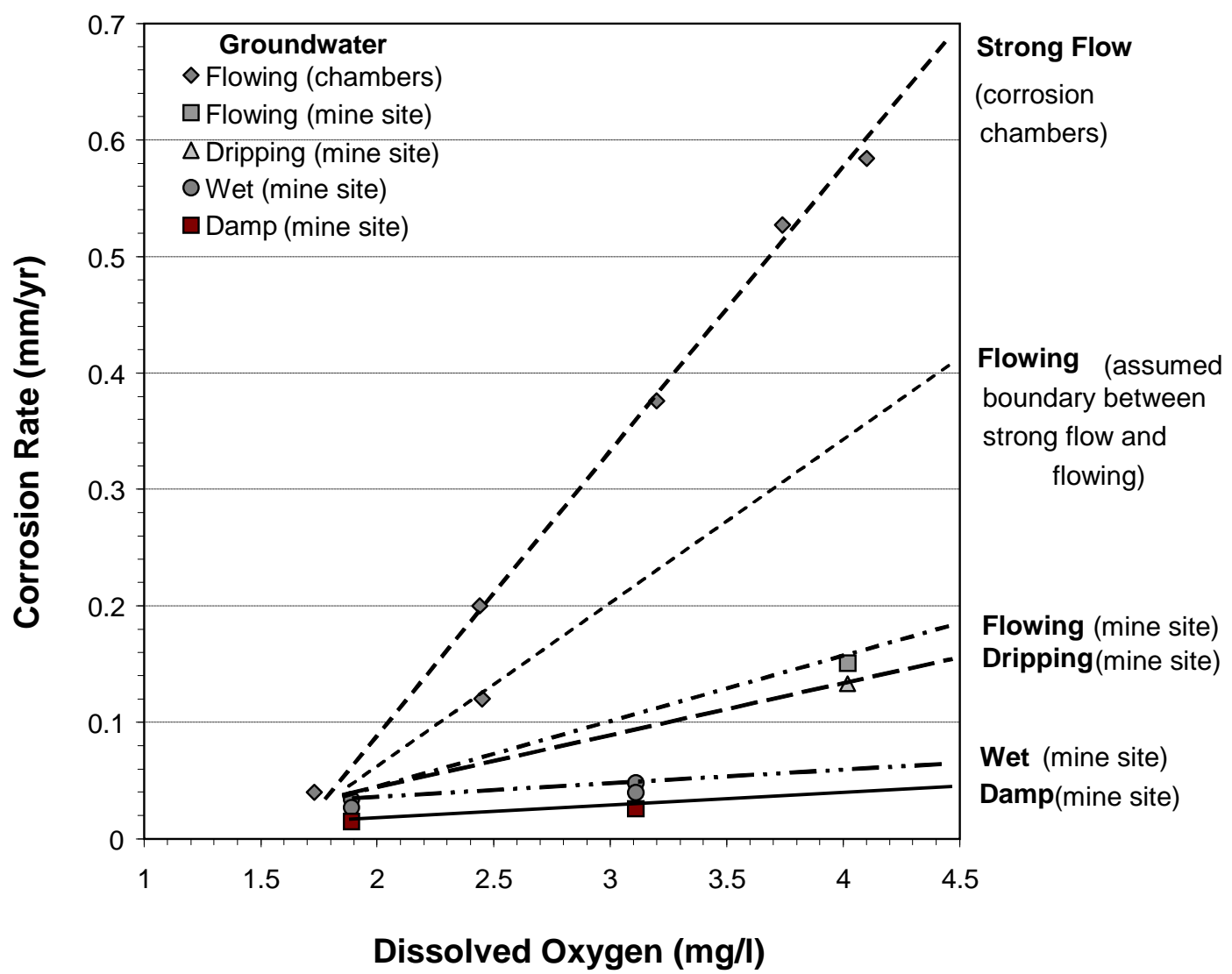

Figure 12 Rates of corrosion in coupons grouped by groundwater flow (Hassell, 2008)

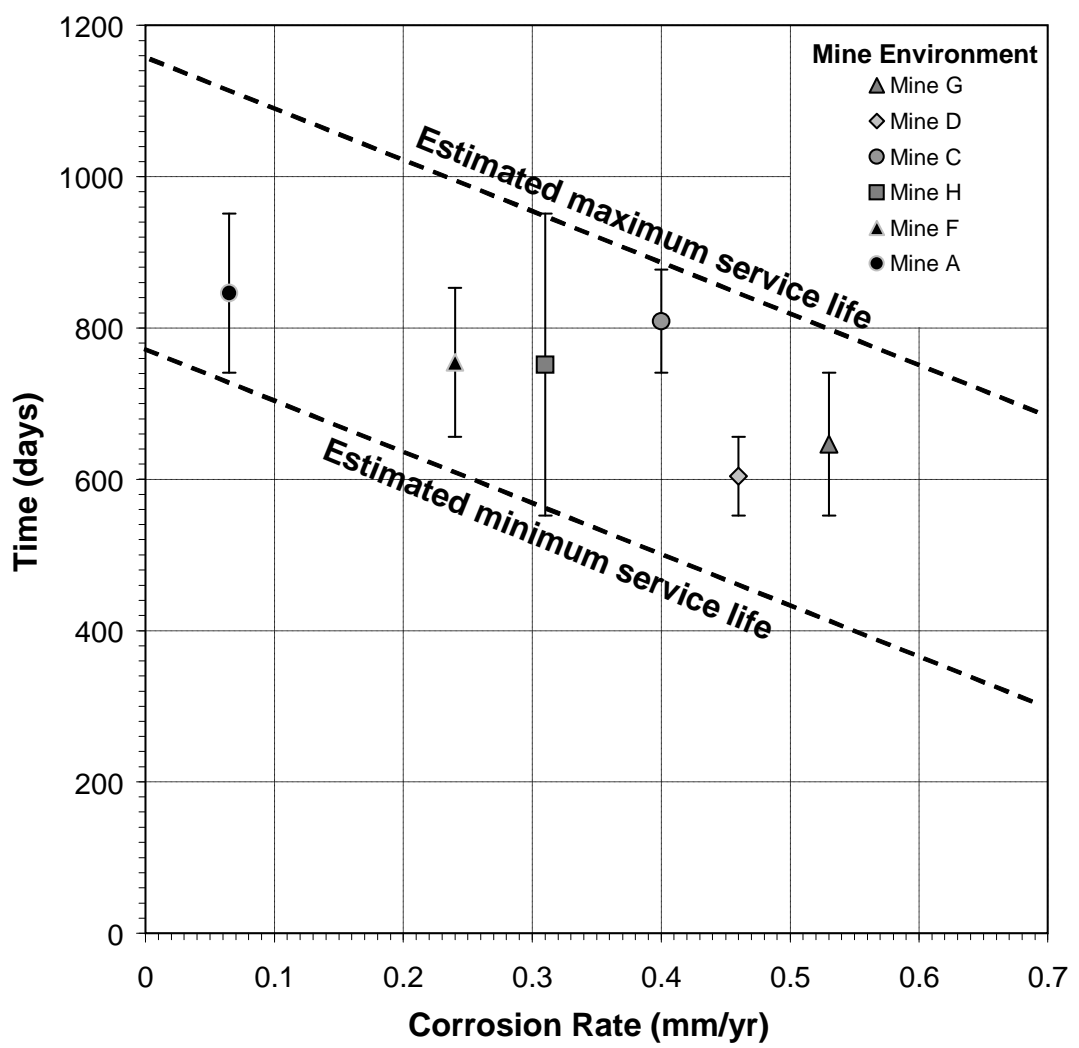

Figure 13 Service life estimates for cable strand in strong groundwater flow Australian mining environments (Hassell, 2008) 


\subsection{Corrosivity of cable bolt anchors}

Corrosion of barrel and wedge anchors and the consequences for the entire cable bolt performance is poorly understood, despite the common use of cable bolts in Australian underground mines since the 1970s. The use of barrel and wedge anchors to restrain plates, straps and mesh in cable bolt reinforcing applications commenced in Australian mines in the early 1980s (Thompson, 2004). Anchor failures after short time durations and under low loads have been observed in several underground mines (Figure 14). Failure is often characterised by the barrel and wedge remaining intact after being found on the floors of drives with no evidence of strand rupture.

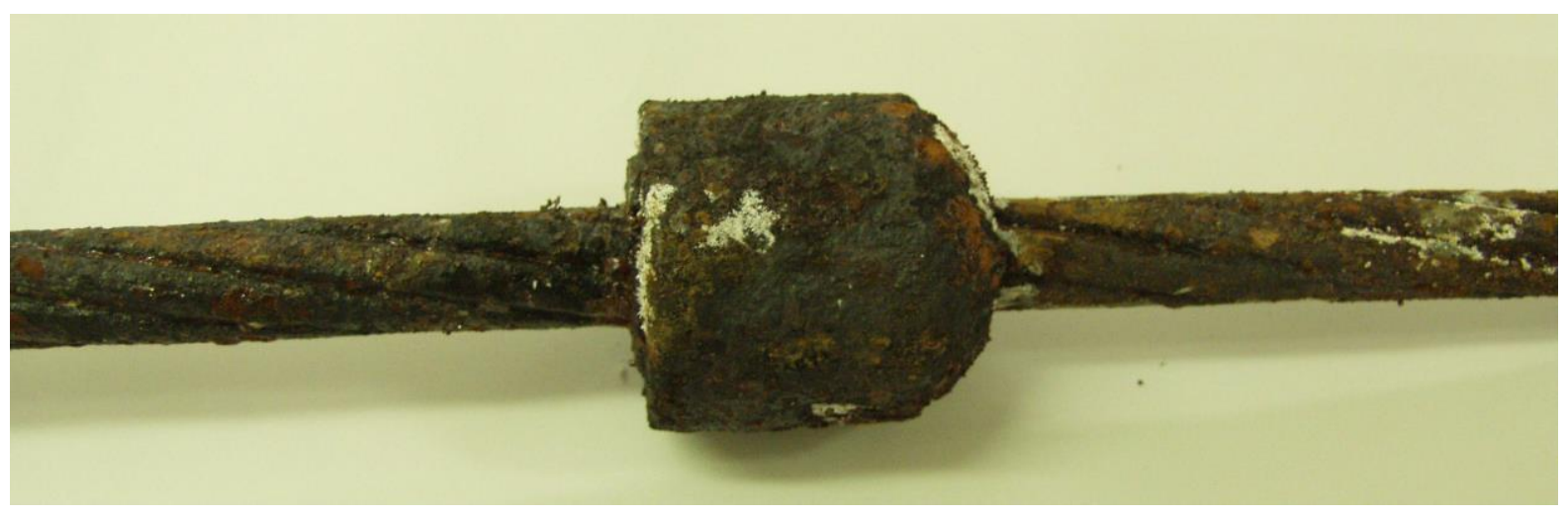

Figure 14 Barrel and wedge corrosion damage observed one year after installation

The corrosion of barrel and wedge anchors is intrinsically linked to the environment in which they are installed. Circumstances in which groundwater is flowing or dripping over the exposed end of the reinforcement are considerably more corrosive than dry environments.

In an attempt to better understand the behaviour of cable bolt anchors, various barrel and wedge anchor configurations were placed within a corrosion chamber to simulate underground environmental conditions (Figure 15). Laboratory pull tests were used to determine the force-displacement responses and the influence of corrosion on the load bearing capacities of the anchors (Hassell and Villaescusa, 2005). A number of corrosion protection methods were trialled. The methods used included galvanising of the barrel as well as three simple and common corrosion inhibitors; grease, bitumen and wax. Some tests were conducted with galvanised strand. The samples were placed in a corrosion chamber with some anchors left outside the chambers for non-corroded reference testing. Subsequent testing of the samples was undertaken after three months, seven months and ten months of exposure (Figure 16).
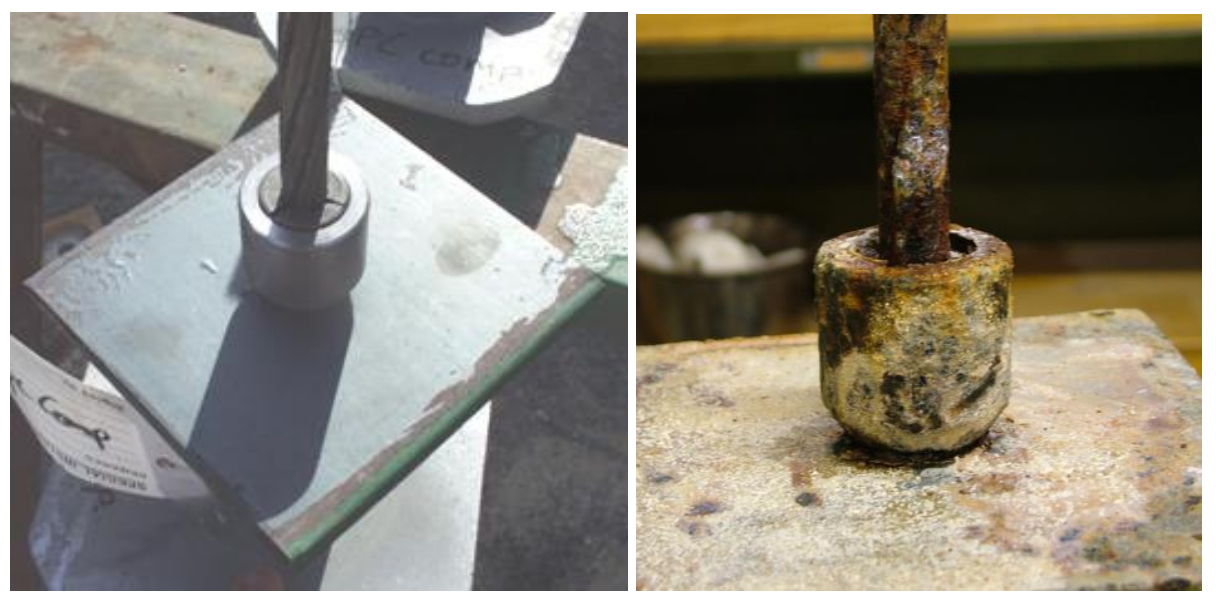

\section{Figure 15 Hemispherical barrel and three-part wedge anchor with compact strand before and after placement in corrosion chambers}


The experiments showed that failure occurred at the wedge/strand interface with the strand pulling through the anchor and was associated with small wedge movement relative to the barrel. Importantly, failure took place at significantly lower loads (ranging from 22 to $111 \mathrm{kN}$ ) than strand force capacity $(250 \mathrm{kN})$ (Figure 16). The internal section of the failed barrel and wedge anchor shown in Figure 17 displayed a build-up of corrosion products on the internal surface of the barrel together with shearing of the wedge teeth.

Corrosion products on the internal surface of the barrel increase the frictional resistance at the barrel/wedge interface, preventing sliding of the wedge relative to the barrel. This in turn prevents the wedge from gripping the strand. That is, the increase in normal force that results from wedge slip does not occur and this means that load must be transferred by the shear resistance of the wedge teeth. It can be shown that this area loaded in shear is very small and the result is shear failure of the teeth. This allows the strand to slip at loads significantly less than the design capacity associated with the tensile strength of the strand.

Anchors that were coated with grease, wax or bitumen had significantly fewer instances of failure (Hassell and Villaescusa, 2005). Consequently, it is recommended that barrel and wedge corrosion protection systems such as a long life lubricant at the barrel/wedge interface and barrier coatings are applied following installation.

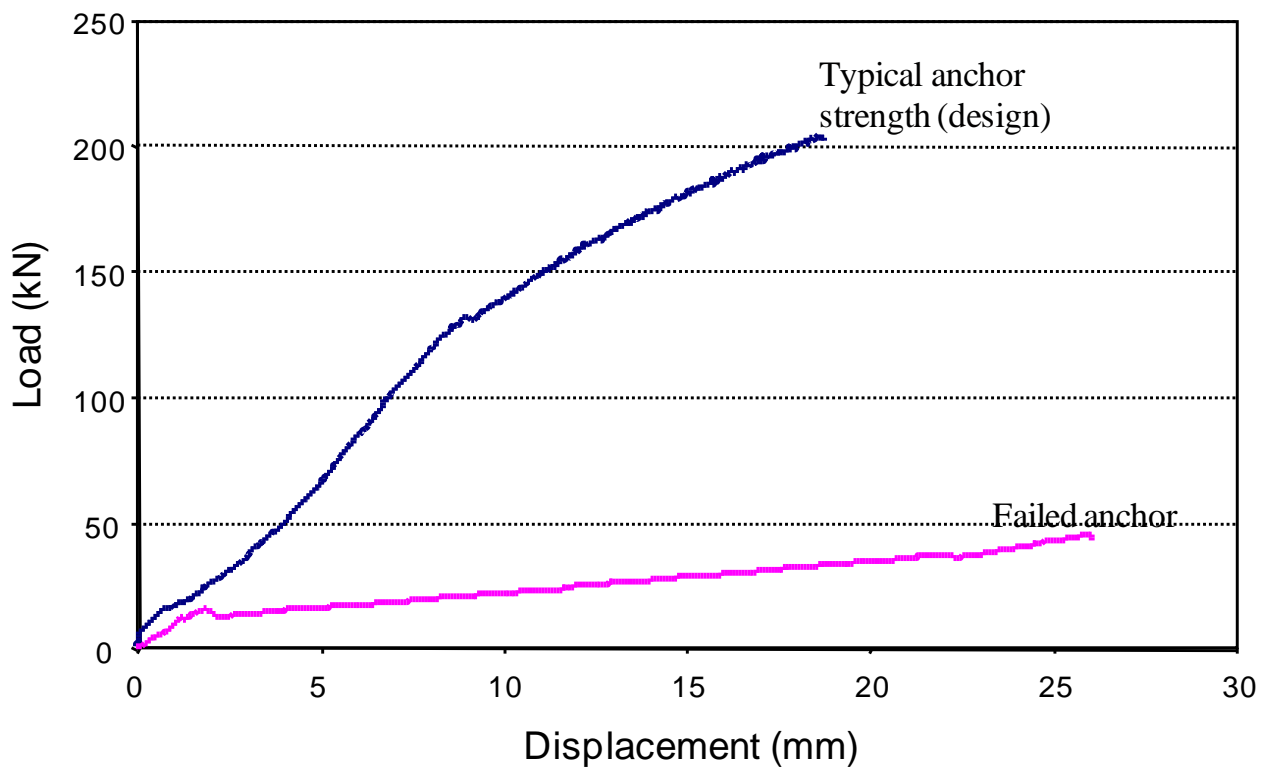

Figure 16 Performance of hemispherical barrel and three part wedge anchor after seven months in corrosion chamber
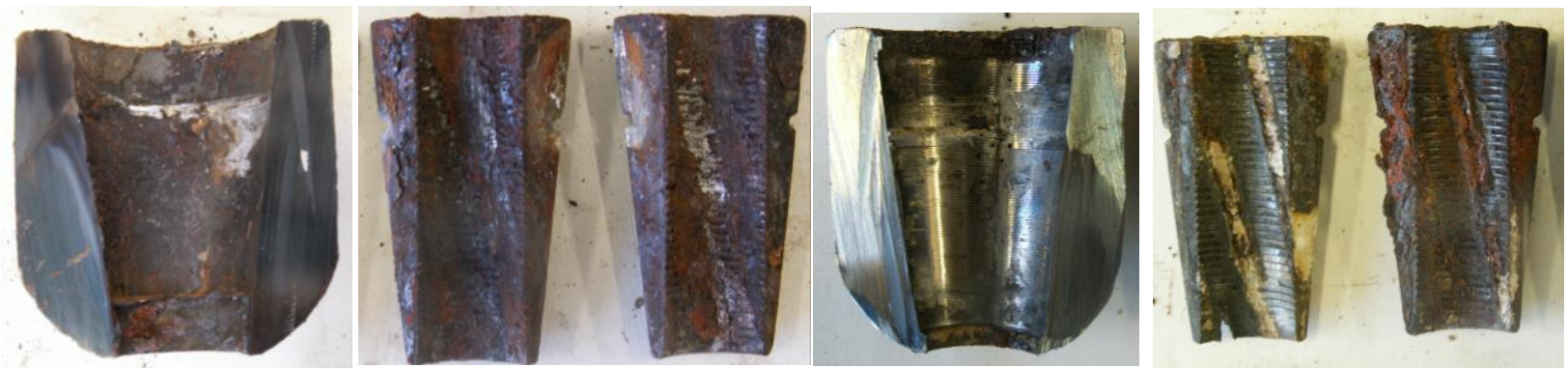

\section{Figure 17 Internal condition of (left) failed and stable (right) barrel and three part wedge anchor}




\section{$5 \quad$ Concluding remarks}

The design of adequate ground support at depth is largely determined by the stress state around the openings and the properties of the rock masses. As underground mines progress deeper into the earth crust, the stress state is such that dynamic failures can be triggered and appropriate stabilisation techniques must be designed and implemented. The results from investigations aimed at quantifying the performance of ground support components have been presented with some suggestions for improved ground support practices. The WA School of Mines continues to undertake ground support research in a wide range of areas with the view of achieving safe and economical extraction under difficult mining conditions at depth.

\section{Acknowledgements}

The financial assistance of the sponsoring mining companies, MERIWA and the CRC Mining in supporting the work of the WASM Rock Mechanics Group is gratefully acknowledged.

\section{References}

Brown, E.T. (2004) The dynamic environment of ground support and reinforcement, in Proceedings Fifth International Symposium on Ground Support, Ground Support in Mining and Underground Construction, E. Villaescusa and Y. Potvin (eds), 28-30 September, Perth, Australia, Balkema, Rotterdam, pp. 3-16.

Hassell, R.C. (2008) Corrosion of rock reinforcement in underground excavations, PhD Thesis, Curtin University, Perth, 276 p.

Hassell, R.C., Villaescusa, E. and Thompson, A.G. (2006) Testing and evaluation of corrosion on cable bolt anchors, in Proceedings 41st US Rock Mechanics Symposium, 17-21 June, Golden, USA, ARMA, Washington DC, Paper 06-996, 11 p.

Hassell, R.C. and Villaescusa, E. (2005) Overcoring techniques to assess in situ corrosion of galvanised friction bolts, in Proceedings 24th international Conference on Ground Control in Mining, S.S. Peng (ed), 2-4 August, Morgantown, USA, University of West Virginia, Morgantown, pp. 349-356.

Hassell, R.C., Villaescusa, E., Thompson, A.G. and Kinsella, B. (2004) Corrosion assessment of ground support systems, in Proceedings Fifth International Symposium on Ground Support, Ground Support in Mining and Underground Construction, E. Villaescusa and Y. Potvin (eds), 28-30 September, Perth, Australia, Balkema, Rotterdam, pp. 529-544.

Potvin, Y., Nedin, P., Sandy, M., Rosengren, K. and Rosengren, M.D. (2001) Towards the Elimination of Rockfall Fatalities in Australian Mines, MERIWA report No. 223, Project No. M341, Government of Western Australia, ACG:1009-01, 54 p.

Player, J.R. (2012) Dynamic testing of rock reinforcement systems. PhD Thesis, Curtin University, Perth, $260 \mathrm{p.}$

Player, J.R., Villaescusa, E. and Thompson, A.G. (2004) Dynamic testing of rock reinforcement using the momentum transfer concept, in Proceedings Fifth International Symposium on Ground Support, Ground Support in Mining and Underground Construction, E. Villaescusa and Y. Potvin (eds), 28-30 September, Perth, Australia, Balkema, Rotterdam, pp. 327-339.

Thompson, A.G., Villaescusa, E. and Windsor, C.R. (2012) Ground support terminology and classification: An Update, Geotechnical and Geological Engineering, DOI 10 1007/s10706-012-9495-4, Vol. 30(3), pp. 553-580.

Thompson, A.G. (2004) Performance of cable bolt anchors - An Update, in Proceedings MassMin 2004, A. Karzulovic and M. Alvaro (eds), 22-25 August, Santiago, Chile, Instituto de Ingenieros de Chile, Santiago, pp. 317-323.

Thompson, A.G., Villaescusa, E. and Player, J.R. (2004) Simulation and analysis of dynamically loaded reinforcement systems, in Proceedings Fifth International Symposium on Ground Support, Ground Support in Mining and Underground Construction, E. Villaescusa and Y. Potvin (eds), 28-30 September, Perth, Australia, Balkema, Rotterdam, pp. 341-355.

Villaescusa, E., Hassell, R.C. and Thompson, A.G. (2008) Development of a corrosivity classification for cement grouted cable strand in underground hard rock mining excavations, Journal of the South African Institute of Mining and Metallurgy, Vol. 108(6), pp. 301-308.

Villaescusa, E., Thompson, A.G. and Player, J.R. (2005) Dynamic testing of rock reinforcement systems, in Proceedings CRC Mining Australian Mining Technology Conference - New Technologies to Produce More with Less, H. Gurgenci, M. Hood, P. Lever and P. Knights (eds), 27-28 September, Fremantle, Australia, The AusIMM, Melbourne, pp. 79-95.

Villaescusa, E., Sandy, M. and Bywater, S. (1992) Ground support investigations and practices at Mount Isa, in Proceedings International Symposium on Rock Support, P.K. Kaiser and D.R. McCreath (eds), 15-19 June, Sudbury, Canada, pp. 185-193.

Windsor, C.R. and Thompson A.G. (1993) Rock Reinforcement - Technology, Testing, Design and Evaluation, Comprehensive Rock Engineering, J.A. Hudson (ed), Pergamon Press, Oxford, Vol. 4, Chapter 16, pp. 451-484.

Wu, Y.K. and Oldsen, J. (2010) Development of a New Yielding Rock Bolt, in Proceedings 44th US Rock Mechanics Symposium and 5th US-Canada Rock Mechanics Symposium, 27-30 June, Salt Lake City, USA, ARMA, Washington DC, Paper 10-197, 6 p. 
Ground support testing 